\title{
Effects of Organizational Justice, Employee Satisfaction, and Gender on Employees' Commitment: Evidence from the UAE
}

\author{
Mohamed E. Ibrahim ${ }^{1} \&$ Ann O. Perez ${ }^{2}$ \\ ${ }^{1}$ College of Business Administration, University of Dubai, United Arab Emirates \\ ${ }^{2}$ Department of Business, Emirates College of Management \& IT, United Arab Emirates \\ Correspondence: Mohamed E. Ibrahim, College of Business Administration, University of Dubai, Al Maktoom \\ Street, Diera, Dubai, United Arab Emirates. Tel: 97-14-207-2605. E-mail: mibrahim@ud.ac.ae
}

Received: September 16, 2013

Accepted: December 20, $2013 \quad$ Online Published: January 20, 2014

doi:10.5539/ijbm.v9n2p45

URL: http://dx.doi.org/10.5539/ijbm.v9n2p45

\begin{abstract}
This paper examined the direct effects of the different dimensions of organizational justice, employees' satisfaction and gender on perceived organizational commitment in the context of UAE service organizations. The paper used a questionnaire administered to a random sample of 174 employees working in 28 different service organizations. We used descriptive statistics, reliability analysis, and regression technique to analyze the data. The results revealed that employees' satisfaction has a direct influence on commitment. However, perceptions of the three organizational justice components (distributive justice, procedural justice, and interactional justice) do not have direct influence on employees' commitment. But they do influence employees' satisfaction. In addition, employee gender, nationality, and tenure do not influence commitment directly or indirectly through satisfaction.
\end{abstract}

Keywords: gender, organizational justice, job satisfaction, organizational commitment, UAE

\section{Introduction}

The past three decades have witnessed an increasing attention to organizational justice and its impacts on different organizational outcomes and employee's behavior (e.g., organizational commitment, job satisfaction, and performance). We believe that the concept of justice is a central notion to our understanding of a wide range of human behaviors in the organizational setting. The concept refers, in general, to the notion of perceived fairness in the workplace.

While extensive research efforts have been exerted in the West, only recently researchers have paid attention to organizational justice and commitment in other cultures. Leung and Stephan (2001) persuasively argued that research on organizational justice must go outside the boundaries of the Western cultural to be able to develop more universal and generalizable theories on organizational justice.

As the next section on the literature review shows, employees' perceptions of justice and satisfaction are important factors that influence employees' commitment. Perceived justice relate to how employees perceive the level of fairness in connection with their performance and its outcomes (e.g., rating, promotion and pay raise). According to Cowherd and Levine (1992), research findings suggest that when employees perceive high level of fairness they become more committed towards their organizations and their performance improves. However, when employees doubt organizational justice, they tend to lose interest in the organization and they do not exhibit willingness to pursue organizational goals. Bhuian, Al-Shammari, and Jefri (1996) reported strong relationship between job satisfaction and commitment.

Metle (1997) also pointed out that the relationship between personal characteristics (e.g., gender) and work attitude might differ among employees in different countries with different cultures. This observation warrants the inclusion of some variables representing personal characteristics in the study of the relationship between organizational justice, job satisfaction, and commitment.

In this paper we examined the direct effects of organizational justice, personal attributes, and job satisfaction on employee commitment in UAE service organizations. The term organizational justice is used in this paper to denote the degree to which employees perceive the overall organizational rules, procedures and policies that are related to their work and its outcome to be fair. It encompasses three components: distributive justice, 
procedural justice, and interactional justice. Job satisfaction relates to the degree to which employees feel positively or negatively about their jobs. Personal attributes includes the basic aspects such as gender, tenure with the company, and nationality.

The paper is organized as follows. The next section reviews prior studies with more emphasis on studies done outside North America and Europe. The third section deals with the methodology we used to obtain our data and analyze them. The fourth section presents the results obtained from the different analyses. The final section discusses the results, their limitations, and the conclusions.

\section{Literature Review}

Several prior studies have addressed different issues related to dimensions of justice, job satisfaction, organizational commitment, and gender effects on employees' behaviors and work outcomes. We reviewed a sample of these studies under four headings. The first reviews some studies on organizational justice. The second reviews some studies on employees' satisfaction. The third reviews some studies on organizational commitment. The last reviews some studies related to the effect of gender on employees' behaviors and work outcomes.

\subsection{Organizational Justice}

Organizational justice has its roots in different fields of study. One of the oldest roots is the field of law which calls for fairness in the processes that resolve disputes and is known as procedural justice. The essence of procedural justice is related to due process (as in the United States), fundamental justice (as in Canada), or natural justice (as in other countries). However, it was the work of Thibau and Walker (1975) on dispute-resolution procedures that augmented the evidence on procedural justice in the context of organizations. Another root of organizational justice is the work of Adams (1963 and 1965) on equity theory. The theory postulates that a person makes judgment of equity or inequity based on an assessment of his contributions to the organization (e.g., knowledge and effort) and his outcomes (e.g., pay and recognition) in comparison to others. Another root of organizational justice has come from the field of political philosophy and ethics that introduced the concept of distributive justice in the context of the social contract and economy by Rawls (1971). However, it is believed that Greenberg (1987) was the first one who coined the term organizational justice to describe the behavior of the organization and the corresponding behavior of employees to feeling of justice or injustice.

Bies and Mong (1986) indicated that justice goes beyond fairness of the job outcomes, which is related to distributive justice, and fairness of organizational procedures, which is related to procedural justice. There are also the elements of how decision makers treat their people and the adequacy with which organizational formal decision making are explained to employees. These additional elements are termed interactional justice.

In a review of published literature on procedural justice, Konovsky (2000) indicated that there is a clear distinction between distributive and procedural justice. She also reviewed both the antecedents and consequences of procedural justice and presented four possible theories that underline procedural justice. In addition, she presented some additional issues dealing with the relationship between procedural justice and distributive justice and possible higher-order effects of procedural justice.

Lau and Moser (2008) examined the role of procedural justice in the context of behavioral effects of nonfinancial performance measures. The study hypothesized that employees would be engaged in favorable behavior when they perceive the performance evaluation measures to be fair. The study used 149 managers from the United Kingdom to assess the perceived fairness of 15 nonfinancial measures of performance that were based on the balanced-scorecard approach. The results of the factor analysis and structured equation analysis indicated that the use of nonfinancial measures was perceived to be procedurally fair. In addition, perceived fairness of performance measures was associated with employees' commitment and enhanced performance.

Hassan and Hashim (2011) examined the difference in perceptions of national and expatriate academics regarding organizational justice in Malaysian institutions of higher education and how organizational justice shapes work outcomes, namely job satisfaction, commitment, and turnover intentions. The study used a random sample of 197 faculty members drawn from several faculties of four public universities in Malaysia and it was divided into two groups: tenured Malaysian nationals and non-tenured expatriates. A questionnaire containing multiple standard measures was used to collect the data. Correlation and regression techniques were used to analyze the data. The results indicated no differences between the two groups regarding organizational justice (distributive, procedural, and interactional), commitment or turnover intentions. However, Malaysian nationals showed significant levels of job satisfaction compared to expatriates. 
Elamin and Alomian (2011) studied the influence of perceived organizational justice on job satisfaction and self-rated performance in Saudi Arabia. They collected their data using a questionnaire completed bya sample of 793 employees working for different organizations representing banks, health care, education, manufacturing, transportation, and communication. Correlation and regression techniques were used to analyze collected data.

The findings of the study revealed that perceptions of organizational justice influenced job satisfaction for both Saudi and non-Saudi employees. The three organizational justice dimensions exhibited significant influence on self-perceived performance. However, procedural justice had a negative effect on self-rated performance.

Nasurdin and Khuan (2011) examined the links between two types of organizational justice (distributive justice and procedural justice) and job performance in terms of task and contextual performance. Age was incorporated in the study as a moderating variable. Data were collected using a questionnaire distributed to a sample of 136 customer-contact employees of the telecommunications industry in Malaysia.

The results indicated that distributive justice had a significant positive relationship with task performance. Similarly, procedural justice had significant positive relation with contextual performance. Age, however, did not moderate the relationship between justice and performance.

Elamin (2012) also examined the influence of perceived organizational justice on two work-related attitudes (job satisfaction and organizational commitment) among Saudi employees. He also examined the differential effects of distributive and procedural justice on these two work-related attitudes. He used a self-administered questionnaire which was distributed to 600 Saudi employees representing 24 organizations in the Eastern province of the country. Correlation and hierarchical regression techniques were used to analyze collected data.

The results indicated that justice significantly influences job satisfaction and commitment. In addition, the differential effects of justice revealed that distributive justice is a stronger predictor of job satisfaction compared to procedural justice. Furthermore, despite the significant positive correlation between procedural justice and organizational commitment, there was no influence of procedural justice on organizational commitment when the influence of interactional justice and distributive justice had been controlled for. The author called on managers to enhance perceptions of justice in the workplace for developing positive work outcomes

\subsection{Employee Satisfaction}

Robie, Ryan, Schmieder, Parra, and Smith (1998) reported on two studies related to job satisfaction. The first was a meta-analysis on the relationship between job level and job satisfaction using 35 published papers. The findings indicated that increased job level was associated with increased job satisfaction level. Some moderators of this relationship were also identified (e.g., culture). The second study examined the relationship using four measures of job level (complexity, complexity ratings, prestige, and special vocational preparation) and five facets of job satisfaction (work, pay, promotion, supervision, and coworkers). The sample consisted of 530 employees selected from four hospitals. The results indicated consistent positive relationship between job level and job facet satisfaction measures.

Ibrahim, Al Sejini, and Al Qassimi (2004) examined the relationship between self-rated performance and job satisfaction among government employees in the United Arab Emirates. The study also addressed the effects of some moderating variables such as gender, age, tenure, marital status, position and nationality on the relationship between performance and satisfaction. Data from 382 employees working at nine government offices were analyzed using reliability, factor analysis, correlation, and regression. The results indicated no significant relationship between self-rated performance and overall job satisfaction. However, self-rated performance, position and nationality were significant factors affecting some job satisfaction facets (i.e., pay and benefits, professional development, and work environment). In addition, age, gender, and marital status had no effect on overall satisfaction or any of its facets.

Zeffane, Ibrahim, and Al Mehairi (2008) explored the impact of job satisfaction on employee attendance and conduct. The authors used secondary-data sets from job satisfaction and performance conducted in a utility company operating in the United Arab Emirates. Job satisfaction was measured using the 20-item Minnesota Satisfaction Questionnaire (MSQ) short form. Performance measures were based on the utility company's employee performance rating system. Analysis of the data revealed significant differences on aspects of job satisfaction and performance between the two gender groups (i.e. males versus females). In general, female respondents were less satisfied with various aspects of their jobs and the job context than their male counterparts. Similarly, they tended to be less performing than their male counterparts on a number of job performance criteria. This pattern is indicative of an underlying linkage between satisfaction and performance, particularly in relation to gender groups. 


\subsection{Employees' Commitment}

Allen and Meyer (1990) indicated that commitment has three components. They are affective commitment, continuance commitment, and normative commitment. Affective commitment relates to emotional attachment of an employee to his organization. Continuance commitment relates to an employee's intrinsic obligation as a result of organizational socialization and the pressure to stay with the organization. On the other hand, normative commitment refers to the employee's choice to stay with the organization or change his job with the chance to incur a loss.

Ko, Price, and Mueller (1997) examined Allen and Meyer's (1990) three components view of organizational commitment using two samples from two organizations in South Korea. The first sample consisted of 278 employees working for a research institute while the second sample consisted of 589 employees working for an airline company. Data were collected by self-administered questionnaires and analyzed using covariance structure analysis. The results indicated that reliability coefficient for the Affective Commitment Scale (ACS) and the Normative Commitment Scale (NCS) were acceptable, whereas the reliability of the Continuance Commitment Scale (CCS) was low. The three scales had acceptable convergent validity, but the ACS and the NCS lacked discriminant validity. The construct validity of the ACS was supported, whereas the construct validity of both the CCS and the NCS were questionable.

Jehanzeb, Rasheed, and Rasheed (2013) investigated effects of training on organizational commitment and turnover intentions in the private sector in Saudi Arabia. Three dimensions of training were considered: training availability, motivation for training, and supervisor's support for training. A self-administered questionnaire was used to collect data from 251 respondents from private organizations. Using regression analyses, the results provided strong support for the hypothesis of the negative relationship between organizational commitment and turnover intention. In addition, training availability was significantly related to organizational commitment and turnover intentions. The results also provide some insight into the impact of some training attributes and organizational commitment on turnover intentions.

\subsection{Gender Effects}

The literature presents mixed results regarding the effect of gender on satisfaction and commitment. Some studies found no differences in the level of satisfaction between males and females (e.g., Dole \& Shroeder, 2001; Manning, 2002; Al-Ajmi, 2006). Ward and Sloane (1998) found that females were more satisfied with their jobs than their male counterparts. Forgionne and Peeters (1982) found that men were more satisfied with their jobs than women.

Mowday, Porter, and Steers (1982), as well as, Mathieu and Zajac (1990) reported significant effects of gender on the levels of organizational commitment. On the other hand, Ngo and Tsang (1998), as well as, Velde, Bossink, and Jansen (2003) reported no significant effects for gender on the levels of commitment.

Marsden, Kalleberg, and Cook (1993) examined the gender differences and factors that arguably enhance or weaken the impact of gender on organizational commitment. They considered both job models and gender models. Job models focus on gender differences in terms of job attributes such as autonomy or rewards. However, gender models emphasize socialization, family ties, and differential labor market opportunities. The results indicated that the primary explanation for the gender difference is that men are more likely to hold jobs with commitment-enhancing features than women. In addition, gender differences in family ties do little to affect the difference between males females' organizational commitment. However, the results indicated that women tend to exhibit slightly greater organizational commitment when job attributes, career variables, and family ties are simultaneously controlled for. The authors concluded that the correlates of organizational commitment do not appear to be different for men and women.

Scandura and Lankau (1997) examined the effects of gender, family responsibility, and flexible work hours on organizational commitment and job satisfaction. They used 160 matched male and female managers employed by different organizations. The results revealed that women who held the perceptions that their organizations offer flexible work hours reported higher levels of organizational commitment and job satisfaction than women who did not. In addition, the effects of flexible work hours on organizational commitment and job satisfaction were stronger for those who had family responsibilities.

Al-Ajmi (2006) examined the effect of gender on employee job satisfaction and organizational commitment in Kuwait. His sample consisted of 436 employees working for five government ministries. Collected data were analyzed using correlation, t-tests, and one-way analysis of variance. The results indicated no significant differences in the level of satisfaction or commitment between males and females. 
Hong, Seung and Park (2012) examined the gender differences and the role of person-organization (P-O) fit in the relationship of work status and organizational commitment. They looked at whether men and women working on part-time or short-term contracts had lower level of commitment to their organizations than their counterparts on regular contracts in Korea. The results showed that person-organization fit mediated the relationship between work status and organizational commitment. In addition, the results indicated that gender moderated the relationship between work status and organizational commitment. For men, the results indicated that regular employees are more committed than non-regular. For women, however, there were no differences detected for regular employees and non-regular employees.

Khalili and Asmawi (2012) investigated the impact of gender differences on organizational commitment in small and medium enterprises (SME). They measured organizational commitment using a scale developed by Allen and Mayer (1990). The scale used three types of commitment: affective commitment, continuance commitment and normative commitment. The sample consisted of 108 employees selected randomly from among employees of a private SME in Iran. Collected data were analyzed using descriptive statistics, reliability alpha, and the independent sample $t$ test. The results indicated that men and women have the same level of affective commitment, continuance commitment, and an overall organizational commitment. However, women seem to have a higher level of normative commitment than men.

\section{Research Methodology}

\subsection{Sample Frame and Sampling Procedure}

The UAE business directory of 2013 compiled by a database company lists more than 300,000 companies in UAE and their contact information (e.g., telephone numbers and e-mails). The company also compiles another directory called top executives directory which lists about 12,000 companies with their contact information and the number of employees. We used this directory as the sampling frame. We reduced the sampling frame to 987 companies using the following two criteria as filters:

a. The company is in the service sector; and

b. The company has a minimum size of 50 employees.

We randomly selected 50 companies (about $5 \%$ ) out of the filtered list to constitute the sample of companies. We contacted these companies for possible participation in the study. Only 28 companies expressed willingness to allow us to survey a sample of their employees. With cooperation from the human resource departments of these 28 companies, we were able to select randomly twelve (12) employees from each company and distribute a total of 336 questionnaires.

\subsection{Development of the Questionnaire}

We used a questionnaire as the primary research instrument to collect the data pertaining to demographics, employees' satisfaction, organizational commitment, and perceived organizational justice. The questionnaire consisted of four parts. The first part asked each respondent to provide some demographic data that included gender, age, tenure, nationality, marital status, and educational level. The second part of the questionnaire included six items intended to measure perceived organizational commitment. The items were taken from the scale of Allen and Meyer (1996). Each participant was asked to provide a score for each item on a seven-point scale ranging from one (strongly disagree) to seven (strongly agree). Three of the six items were positively-worded while the other three items were negatively-worded. The negatively-worded items were to be reverse-coded at the time of the analysis.

The third part of the questionnaire contained 4 items measuring employee's global satisfaction. These items were taken from the instrument developed by Hoppock (1935). Each participant was asked to select from among seven statements the one that best represents his opinion or perception.

The fourth part of the questionnaire included 20 items intended to measure perceived organizational justice. The items were taken from Niehoff and Moorman (1993). Five items represented distributive justice, six items represented procedural justice, and the remaining nine items represented the interactional justice. Each participant was asked to provide a score for each item on the extent to which he agrees or disagrees with the item using a seven-point scale ranging from one (strongly disagree) to seven (strongly agree). A copy of the questionnaire is included in the Appendix.

\subsection{Research Model and Hypotheses}

Based on the literature review, this paper used the following representation of a theoretical model. The model contains six variables. The far right variable (commitment) represents the dependent variable while the other 
five variables represent the main independent variables for commitment. The model depicts the relationships among these variables which are used as the basis for developing the following research hypotheses that are stated in the null form:

$\mathrm{H}_{1}$ : There is no relationship between each of the three types of organizational justice and employee's commitment.

$\mathrm{HO}_{2}$ : There is no relationship between job satisfaction and employee's commitment

$\mathrm{HO}_{3}$ : There is no relationship between gender and employee's commitment.

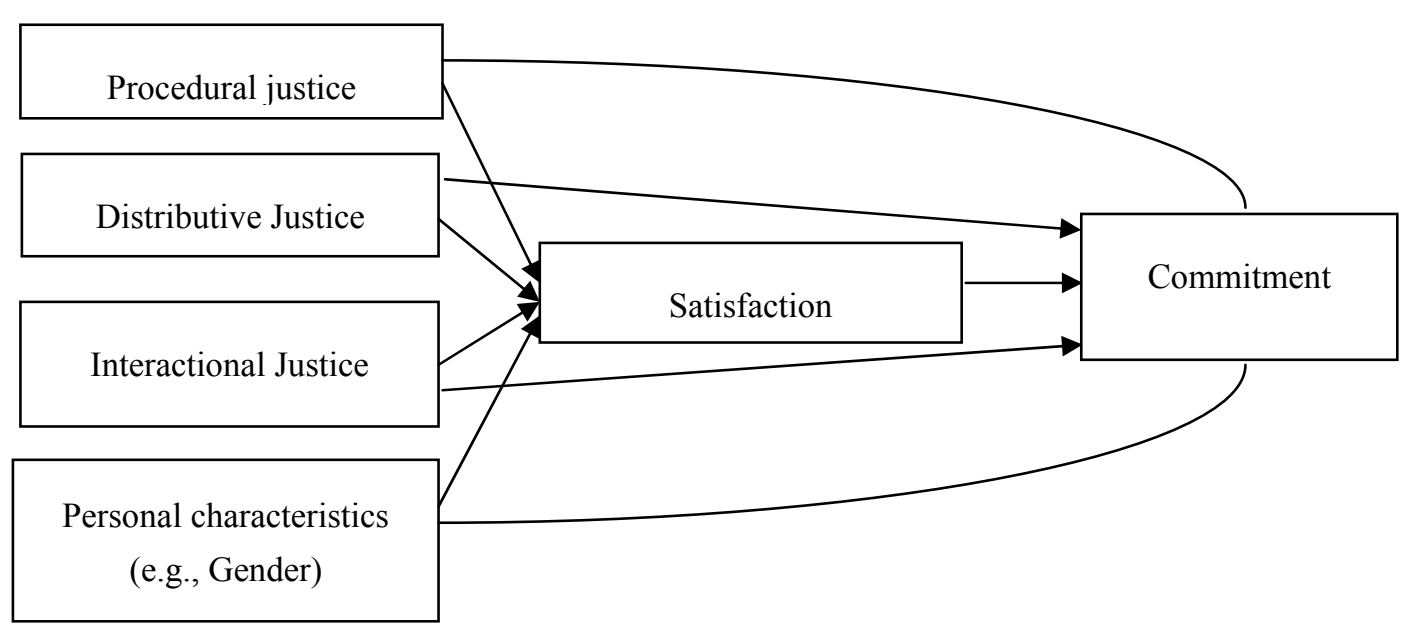

The direct effects on commitment according to the above model are expressed as follows:

$$
Y=\alpha+\beta_{1} X_{1}+\beta_{2} X_{2}+\beta_{3} X_{3}+\beta_{4} X_{4}+\beta_{5} X_{5}+\beta_{6} X_{6}+\beta_{7} X_{7}+\varepsilon
$$

Where,

$\mathrm{Y}=$ refers to the level of commitment;

$\mathrm{X}_{1}=$ refers to perceived distributive justice;

$\mathrm{X}_{2}=$ refers to perceived procedural justice;

$\mathrm{X}_{3}=$ refers to perceived interactional justice;

$\mathrm{X}_{4}=$ refers to job satisfaction;

$\mathrm{X}_{5}=$ refers to length of time with the company;

$\mathrm{X}_{6}=$ refers to gender;

$\mathrm{X}_{7}=$ refers to nationality;

$\alpha, \beta=$ regression parameters;

$\varepsilon=$ error term.

\subsection{Variables and Measures}

This study used commitment as the dependent variable while the three types of organizational justice, employee's attributes (e.g., gender) and job satisfaction were used as the independent variables. These variables and their measurements are explained briefly below.

Organizational Justice: This variable refers to the notion of fairness in an organizational setting. Organizational justice has three separate components: distributive justice, procedural justice, and interactional justice. Each of these three components was measured using the scale developed by Niehoff, and Moorman (1993). The scale has 20 items. The first 5 items represent distributive justice. The second six items represent procedural justice. The remaining nine items represent the interactional justice. Each participant was asked to score each of the 20 items on a seven-point scale. Summation of the scores of the items for each component provided the score for the component with a minimum of five and a maximum of 35 (for distributive justice), a minimum of six and a 
maximum of 42 (for procedural justice), and a minimum of nine and a maximum of 63 (for interactional justice).

Job Satisfaction: This variable refers to how people feel about their jobs (Spector, 1997). There are different instruments designed to measure job satisfaction in different settings (e.g., Hoppock 1935; Hackman \& Oldham, 1975; Smith et al., 1987; Spector, 1997). We used the short form of the Hoppock's job satisfaction Blank (1935). Our choice of this instrument is based on the supportive test results reported by several researchers. For example, Crites (1965), in a review of several job satisfaction instruments concluded that the Hoppock instrument is the best because of its ease of administration and scoring, its internal consistency, and its validity. McNichols, Stahl, and Manly (1978) demonstrated that the instrument performed well in terms of items' distribution, construct, convergent and concurrent validity across four samples totaling over 29,000 subjects that were drawn from four populations. The instrument had high reliability coefficients (alpha values) that ranged from 0.76 to 0.89 .

The instrument comprises four items used to measure global job satisfaction. Each item contains seven statements that each individual respondent was asked to select the statement that best represents his opinion or perception. An example of an item is: "How well do you like your Job? Responses range from one (I hate it) to seven (I love it). For statistical analysis, scores of two items (b and d) were reversed. Summation of the scores of the four items yielded the measure of the job satisfaction with a minimum score of four and a maximum of 28 .

Employee's commitment: This variable refers to an employee's psychological attachment to the organization. Porter, Stears, Mowday, and Boulian (1974) developed a 15-item measure of commitment that is known as the organizational commitment questionnaire (OCQ). Allen and Meyer (1990) developed a 24-item measure of the three types of commitment (eight items for each type). But they later (Allen \& Meyer, 1996) modified the instrument to have only18 items in total where each component of commitment is represented by six items.

Although there is a substantial amount of evidence to support Allen and Meyer's three components of commitment and their measurement (e.g., Meyer, Allen, \& Smith, 1993; Dunham, Grube, \& Castaneda, 1994; Shore, Barkside, \& Shore, 1995), the reported results of Ko, Price, and Mueller (1997) and their discussions indicated some conceptual and methodological problems with continuance and normative commitment. They also indicated that affective commitment is conceptually and methodological sound. Accordingly, we employed only the affective component as the only measure of commitment. It was measured by six items adopted from Allen and Meyer (1996) with modified wording for the first item as suggested by Jaros (2007). Part II of the questionnaire included these items and each participant was asked to score each of the 6 items on a seven-point scale. Summation of the scores of these items after reverse coding items 2, 4, and 6 provided the score for this variable with a minimum of six and a maximum of 42 .

Personal Characteristics: These characteristics refer to the personal attributes that may affect an individual's psychological attachment to the organization and his feelings about his own job. These attributes may include gender, nationality, and tenure, among others. Mathieu and Zajac (1990) and Aven, Parker, and McEvoy (1993) indicated that factors such as age and tenure tend to affect individual's level of commitment. This paper used three personal attributes: gender, nationality, and tenure. Each participant was asked to provide such information in part I of the questionnaire. Tenure was measured in terms of the number of years with the organization. Gender was measured as a dichotomous variable which was coded zero (0) for females and one (1) for males. Nationality was also measured as a dichotomous variable which was coded zero (0) for nationals of UAE and one (1) for non-UAE nationals.

\section{Data Analysis and Results}

We used the Statistical Package for Social Sciences (SPSS) to screen and analyze collected data. We performed a reliability analysis usingthe coefficient Cronbach Alpha to judge the internal consistency of the multi-item measures. We also performed regression analysis to judge the direct effects of the components of organizational justice, job satisfaction, and personal attributes on employee's commitment. We performed a second regression to judge the direct effects of organizational justice components and personal attributes on employee's satisfaction to judge its instrumentality to influence commitment.

\subsection{Survey Responses}

As indicated earlier, we distributed 336 questionnaires to a random sample of employees working for 28 service organizations. We received 174 completed questionnaires within six weeks after distribution. This represents about $52 \%$ response rate. Table 1 presents the frequency distribution of the demographic variables of the sample. 
Table 1. Frequency distribution of categorical variables

\begin{tabular}{llll}
\hline Variable & Category & Frequency & Percentage \\
\hline Gender & Male & 69 & $39.7 \%$ \\
& Female & 105 & $60.3 \%$ \\
Marital status & Single & 46 & $25.4 \%$ \\
& Married & 123 & $70.7 \%$ \\
Nationality & Other & 5 & $02.9 \%$ \\
& UAE national & 80 & $46.0 \%$ \\
Educational level & Non-UAE national & 94 & $54.0 \%$ \\
& Lower than Bachelor degree & 4 & $02.3 \%$ \\
& Bachelor degree & 158 & $91.4 \%$ \\
\hline
\end{tabular}

The table above shows that the majority of the respondents were males while females represented only about $40 \%$ of the sample. In addition, the most of the respondents were married and hold bachelor degrees. Furthermore, a sizable portion of the sample represented UAE nationals (46\%).

Table 2 presents basic descriptive statistics of the non-categorical variables. The table shows that respondents' ages varied from 19 to 59 and the average age of a respondent was about 35 years, while the average number of the years a respondent has been with his organization was about 6 years. This may imply either a high turnover rate among the employees or the organizations are young in their industry.

Table 2. Descriptive statistics of non-categorical variables

\begin{tabular}{|c|c|c|c|c|}
\hline$\underline{\text { Variable }}$ & Minimum & Maximum & Mean & Std. Deviation \\
\hline Age & 19.00 & 59.00 & 35.3908 & 9.16245 \\
\hline Tenure & 02.00 & 20.00 & 05.7011 & 4.18258 \\
\hline Distributive Justice & 20.00 & 35.00 & 29.3966 & 2.92847 \\
\hline Procedural Justice & 24.00 & 42.00 & 36.0172 & 4.14265 \\
\hline Interactional Justice & 30.00 & 60.00 & 42.9138 & 5.44956 \\
\hline Job Satisfaction & 16.00 & 28.00 & 23.5345 & 2.72358 \\
\hline Organizational commitment & 25.00 & 41.00 & 32.4713 & 3.51821 \\
\hline
\end{tabular}

Table 2 also shows that the average score for the research variables was toward the high end of the scale. This indicates that feeling of justice is high as well as their satisfaction. The average score of commitment seems to indicate that the sample respondents are committed employees.

\subsection{None-Response Bias}

Most of the measures we used in this paper were adopted from prior research where their validity and reliability have already been established. However, we needed to test first for possible none response bias since about $48 \%$ of the subjects did not respond. We employed the split-half approach to test for such a bias. This approach requires splitting the sample into two halves (e.g., early responses versus late responses or odd numbered cases versus even numbered cases). In this paper we used early responses versus late responses and compared the mean values of selected items (age, tenure, and organizational commitment) using t-tests for equality of means. The results indicated no significant differences. Thus we conclude that possible effects of non-response bias, if any, are minor.

\subsection{Reliability Analysis}

We performed a reliability analysis using Cronbach Alpha in order to judge the internal consistency of the multi-item measures. According to Price (1997), a coefficient alpha of at least 0.7 indicates that the data are reliable. Table 3 reports the obtained coefficients. 
Table 3. Results of reliability analysis

\begin{tabular}{lcc}
\hline Scale & Items & Cronbach Alpha \\
\hline Distributive Justice & 5 & .831 \\
Procedural Justice & 6 & .944 \\
Interactional Justice & 9 & .945 \\
Organizational Commitment & 6 & .823 \\
Employees' Satisfaction & 4 & .862 \\
\hline
\end{tabular}

Table 3 shows that all reliability coefficients are above the cut-off point of 0.7 . The table also shows that procedural justice and interactional justice have the highest level of reliability as compared to the other three measures.

\subsection{Regression Results}

We performed regression analyses to test the direct effects of the variables stated in the research model on both commitment and satisfaction. Table 4 shows the direct effects of the independent variables on commitment. The table shows that the model is statistically significant $(\mathrm{F}=2.325, \mathrm{P} . \leq 0.027)$. However, its explanatory power as represented by $\mathrm{R}^{2}$ is low (.051). This indicates that the model seems to be missing some other important variables.

Table 4. Regression results of direct effects on commitment

\begin{tabular}{lccc}
\hline Variable & $\boldsymbol{\beta}$ & $\mathbf{t}$ & Significance \\
\hline Distributive Justice & .018 & .102 & .919 \\
Procedural Justice & .015 & .087 & .931 \\
Interactional Justice & -.131 & -1.617 & .108 \\
Employee Satisfaction & .273 & 3.480 & .001 \\
Gender & .099 & 1.271 & .205 \\
Nationality & -.094 & -1.244 & .215 \\
Tenure & .071 & .915 & .361 \\
\hline
\end{tabular}

$\mathrm{R}^{2}=.051 ; \mathrm{F}=2.325, \mathrm{p} \leq 0.027 ; \mathrm{n}=174$.

Table 4 also shows that only one of the independent variables (employee satisfaction) is statistically significant $(\mathrm{t} \geq 2, \mathrm{P} \leq 0.001)$ and the remaining variables related to organizational justice and personal attributes are insignificant. These results indicate that satisfied employees tend to have higher levels of commitment. In addition, personal attributes and organizational justice do not affect organizational commitment. We, therefore, conclude that satisfaction has a significant statistical impact on organizational commitment. Accordingly, the results fail to reject the hypothesized no relationship between organizational justice $\left(\mathrm{H}_{01}\right)$ as well as the effects of gender $\left(\mathrm{H}_{03}\right)$. However, the results reject the hypothesized no relationship between satisfaction and organizational commitment $\left(\mathrm{H}_{02}\right)$.

Table 5 reports the results of a regression analysis that considered the direct effects of organizational justice and personal attributes on satisfaction. The table shows that the model is statistically significant $(\mathrm{F}=3.292$, P. $\leq$ 0.004). However, its explanatory power as represented by its $\mathrm{R}^{2}$ is low (.106). This indicates that the model is missing some other important variables.

Table 5 also shows that the three components of organizational justice are statistically significant $(\mathrm{t} \geq 1.987, \mathrm{P} \leq$ 0.049 ) while the variables representing personal attributes are insignificant. Given these results and the results reported in Table 4, one can conclude that satisfaction is an absorber of the effects of organizational justice and is instrumental in affecting organizational commitment. That is, the effects of organizational justice on organizational commitment are manifested through satisfaction. In addition, personal attributes variables (i.e., gender, nationality, and tenure) have no direct or indirect effects on organizational commitment. 
Table 5. Regression results of direct effects on satisfaction

\begin{tabular}{lccc}
\hline Variable & $\boldsymbol{\beta}$ & $\mathbf{T}$ & Significance \\
\hline Distributive Justice & -.346 & -2.076 & .039 \\
Procedural Justice & .333 & 1.987 & .049 \\
Interactional Justice & -.291 & -3.803 & .000 \\
Gender & .110 & 1.437 & .153 \\
Nationality & .030 & .409 & .683 \\
Tenure & .064 & .835 & .405 \\
\hline
\end{tabular}

$\mathrm{R}^{2}=.106 ; \mathrm{F}=3.292, \mathrm{p} \leq 0.004 ; \mathrm{n}=174$.

\section{Conclusions}

Over the years, researchers in the fields of psychology and organizations have paid attention to different subjects related the workplace. These subjects include gender differences, job satisfaction, organizational commitment, and organizational justice, among others. Many issues related to these subjects have proven to have different impacts on organizational outcomes and employee's behavior.

This paper tested the direct effect of organizational justice (and its components), personal attributes, and job satisfaction on organizational commitment. Obtained results indicate that there were no significant direct effects of organization justice and personal attributes on organizational commitment. However, the direct effect of job satisfaction on organizational commitment was significant. In addition, organizational justice had direct effect on satisfaction. Thus, we concluded that job satisfaction is instrumental in reflecting the effects of organizational justice on organizational commitment.

Since the reported results in the literature were mixed results, we also considered our results to be mixed as they confirm the results of some prior studies and disconfirm some others. The results, however, are subject to some limitations. First, the choice of the instruments used was based on preference. Use of other instruments may have some possible effects on the results. Second, the study used only three variables to represent personal attributes. Other variables (e.g., personal beliefs and age) may have possible effects on the results. Third, we used a linear model to test the hypothesized relationships. Other models may prove to be superior to the one used and it is possible that the results may differ. Finally, we did not address the issue of possible interactions among the independent variables. Using a different methodology (e.g., structured equation modeling) may give different results.

We recommend more similar studies to the current one with more additional variables that may capture the effects of different organizational settings (e.g., organizational culture) and additional personal characteristics (e.g., personal beliefs). We also recommend replication of this study using different samples from other countries in the gulf area.

\section{Acknowledgements}

We acknowledge the helpful comments received from Julie D. Cue, the editor, and two anonymous reviewers on an earlier version of this paper. We also acknowledge the assistance provided by Judith La Victoria with data entry.

\section{References}

Adams, J. S. (1963). Towards an understanding of inequity. Journal of Abnormal and Social Psychology, 67(5), $422-436$.

Adams, J. S. (1965). Inequity in social exchange. In L. Berkowitz (Ed.), Advances in experimental social psychology. New York, NY: Academic Press.

Al-Ajmi, R. (2006). The Effect of gender on job satisfaction and organizational commitment in Kuwait. International Journal of Management, 23(4), 838-844.

Allen, N. J., \& Meyer, J. P. (1990). The Measurement and antecedents of affective, continuance and normative commitment to the organization. Journal of Occupational Psychology, 63(1), 1-18. http://dx.doi.org/10.1111/j.2044-8325.1990.tb00506.x.

Allen, N. J., \& Meyer, J. P. (1996). Affective, continuance and normative commitment to the organization: An examination of construct validity. Journal of Vocational Behavior, 49(3), 252-276. http://dx.doi.org/10.1006/jvbe.1996.0043. 
Aven, F., Paker, B., \& McEvoy, G. (1993). Gender and attitudinal commitment to organizations: A $\begin{array}{llll}\text { meta-analysis. Journal of } & \text { Business }\end{array}$ http://dx.doi.org/10.1016/0148-2963(93)90043-O.

Bies, R., \& Mong, J. (1986). Interactional justice: Communication criteria of fairness. In R. J. Liwick, B. H. Sheppard, \& B. H. Bazerman (Eds.), Research on Organization in Organizations. Greenwich, CT: JAI Press.

Bhuian, S. N., Al-Shammari, E. S., \& Jefri, O. A. (1996). Organizational commitment, job satisfaction and job characteristics. International Journal of Commerce \& Management, 6(3/4), 57-79. http://dx.doi.org/10.1108/eb047336

Cowherd, D., \& Levine, D. (1992). Product quality and pay equity between lower-level employees and top management: An investigation of distributive justice theory. Administrative Science Quarterly, 37(2), $302-320$.

Crites, J. (1965). Measurementof vocational maturity in adolescence: Attitude test of the vocational development Inventory. Psychological Monographs, 79(2).

Dole, C., \& Shroeder, R. (2001). The impact of various factors on the personality, job satisfaction and turnover intentions of professional accountants. Managerial Auditing Journal, 16(4), 234-245. http://dx.doi.org/10.1108/02686900110389188

Dunham, R. B., Grube, J. A., \& Castaneda, M. B. (1994). Continuance commitment: The utility of an integrative definition. Journal of Applied Psychology, 79(3), 370-380. http://dx.doi.org/10.1037/ 0021-9010.79.3.370.

Elamin, A. (2012). Perceived organizational justice and work-related attitudes: A study of Saudi employees. World Journal of Entrepreneurship, Management and Sustainable Development, 8(1), 71-88. http://dx.doi.org/10.1108/20425961211221633

Elamin, A., \& Alomain, N. (2011). Does organizational justice influence job satisfaction \& self-perceived performance in Saudi Arabia Work Environment? International Management Review, 7(1), 38-49.

Forgionne, G., \& Peeters, V. (1982). Differences in job motivation and satisfaction among female and male managers. Human Relations, 35(2), 101-118. http://dx.doi.org/10.1177/001872678203500202

Greenberg, J. (1987). A taxonomy of organizational justice theories. Academy of Management Review, 12(1), $9-22$.

Hackman, J. R., \& Oldham, G. R. (1975). Development of the Job Diagnostic Survey. Journal of Applied Psychology, 60(2), 159-170. http://dx.doi.org/10.1037/h0076546

Hassan, A., \& Hashim, J. (2011). Role of organizational justice in determining work outcomes of national and expatriate academic staff in Malaysia. International Journal of Commerce and Management, 21(1), 82-93. http://dx.doi.org/10.1108/10569211111111711

Hong, S., Seung, J. Y., \& Park, W. (2012). Work status, gender, and organizational commitment among Korean workers: The mediating role of person-organization fit. Asia Pacific Journal of Management, 29(4), 1105-1129. http://dx.doi.org/10.1007/s10490-011-9248-6

Hoppock, R. (1935). Job Satisfaction. New York, NY: Harper and Row.

Ibrahim, M. E., Al Sejini, S., \& Al Qassimi, O. A. (2004). Job satisfaction and performance of government employees in UAE. Journal of Management Research, 4(1), 1-11.

Jaros, S. (2007). Meyer and Allen model of organizational commitment: Measurement issues. The ICFAI Journal of Organizational Behavior, 6(4), 7-25.

Jehanzeb, K., Rasheed, A., \& Rasheed, M. (2013). Organizational commitment and turnover intentions: Impact ofemployee's training in private sector of Saudi Arabia. International Journal of Business and Management, 8(8), 79-90. http://dx.doi.org/10.5539/ijbm.v8n8p79

Khalili, A., \& Asmawi, A. (2012). Appraising the impact of gender differences on organizational commitment: Empirical evidence from a private SME in Iran. International Journal of Business and Management, 7(5), 100-110. http://dx.doi.org/10.5539/ijbm.v7n5p100

Ko, J., Price, J., \& Mueller, C. (1997). Assessment of Meyer and Allen's three-component model of organizational commitment in South Korea. Journal of Applied Psychology, 82(6), 961-973.

Konovsky, M. A. (2000). Understanding procedural justice and its impact on business organizations. Journal of 
Management, 26(3), 489-512. http://dx.doi.org/10.1177/014920630002600306.

Lau, C. M., \& Moser, A. (2008). Behavioral effects of nonfinancial performance measures: The role of procedural fairness. Behavioral Research in Accounting, 20(2), 55-71. http://dx.doi.org/10.2308/bria.2008.20.2.55

Leung, K., \& Stephan, W. G. (2001). Social justice from a cultural perspective. In Matsumoto, D. (Ed.), The handbook of culture and psychology (pp. 375-378). New York, NY: Oxford University Press.

Manning, T. (2002). Gender, managerial level, transformational leadership, and work satisfaction. Women in Management Review, 17(5/6), 207-216. http://dx.doi.org/10.1108/09649420210433166

Marsden, P. V., Kalleberg, A. L., \& Cook, M. C. (1993). Gender differences in organizational commitment influences of work positions and family roles. Work and Occupations, 20(3), 368-390. http://dx.doi.org/10.1177/0730888493020003005

Mathieu, J. E., \& Zajac, D. M. (1990). A review and meta-analysis of the antecedents, correlates and consequences of organizational commitment. Psychological Bulletin, 108(2), 171-194. http://dx.doi.org/10.1037//0033-2909.108.2.171

Metle, C. (1997). The relationship between age and job satisfaction: A study among female bank employees in Kuwait. International Journal of Management, 14(4), 654-666.

Meyer, J. P., Allen, N. J., \& Smith, C. A. (1993). Commitment to organizations and occupations: extension and test of a three-component conception. Journal of Applied Psychology, 78(4), 538-551. http://dx.doi.org/10.1037/0021-9010.78.4.538

McNichols, C. W., Stahl, M. J., \& Manly, R. T. (1978). A validation of Hoppock's job satisfaction measure, Academy of Management Journal, 21(4), 737-742. http://dx.doi.org/10.2307/255715

Mowday, R. T., Porter, L. M., \& Steers, R. (1982). Organizational linkages: The psychology of commitment, absenteeism and turnover. San Diego, CA: Academic Press.

Nasurdin, A. M., \& Khuan, S. L. (2011). Organizational justice, age, and performance connection in Malaysia. International Journal of Commerce and Management, 21(3), 273-290. http://dx.doi.org/10.1108/10569211111165316

Ngo, H., \& Tsang, A. (1998). Employment practices and organizational commitment: Differential effects for men and women? International Journal of Organizational Analysis, 6(3), 251-266. http://dx.doi.org/10.1108/eb028887

Niehoff, B. P., \& Moorman, R. H. (1993). Justice as a mediator of the relationship between methods of monitoring and organizational citizenship behavior. Academy of Management Journal, 36(3), 527-556. http://www.jstor.org/stable/256591

Porter, L., Steers, R., Mowday, R., \& Boullian, P. (1974). Organizational commitment, job satisfaction and turnover among psychiatric technicians. Journal of Applied Psychology, 59(5), 603-609. http://dx.doi.org/10.1037/h0037335

Price, J. L. (1997). Handbook of organizational measurement. International Journal of Manpower, 18(4/5/6), 305-558. http://dx.doi.org/10.1108/01437729710182260

Rawls, J. (1971). A theory of justice. The Belknap Press of Harvard University Press.

Robie, C., Ryan, A., Schmieder, R., Parra, L., \& Smith, P. (1998). The relation between job level and job satisfaction, Group \& Organization Management, 23(4), 470-495. http://dx.doi.org/10.1177/1059601198234007

Scandura, T. A., \& Lankau, M. J. (1997). Relationships of gender, family responsibility and flexible work hours to organizational commitment and job satisfaction. Journal of Organizational Behavior, 18(4), 377-391. http://dx.doi.org/10.1002/SICI1099-1379 (199707)18:4.377

Shore, L., Barksdale, K., \& Shore, T. (1995). Managerial perceptions of employee commitment to the organization.Academy of Management Journal, 38(6), 1593-1615. http://www.jstor.org/stable/256845

Smith, P. C., Balzer, W. K., Brannick, M., Chia, W., Eggleston, S., Gibson, W., Johnson, B., Josephson, H., Paul, K., Reilly, C., \& Whalen, M. (1987). The revised JDI: A facelift for an old friend. The Industrial-Organizational Psychologist, 24(4), 31-33.

Spector, P. E. (1997). Job Satisfaction: Application, assessment, causes, and consequences. Thousand Oak, CA: 
SAGE Publications.

Thibau, J., \& Walker, L. (1975). Procedural justice: A psychological analysis. Hillsdale, NJ: Lawrence Erlbaum Associates.

Velde, M., Bossink, C., \& Jansen, P. (2003). Gender differences in the influence of professional tenure on work attitudes. Sex Roles: A Journal of Research, 49(3/4), 153-169.

Ward, M., \& Sloane, P. (1998). Job satisfaction: The Scottish academic profession. Mimeo: University of Aberdeen.

Zeffane, R., Ibrahim, M. E., \& Al Mehairi, R. (2008). Exploring the differential impact of job satisfaction on employee attendance and conduct: The case of a utility company in the United Arab Emirates. Employee Relations, 30(3), 237-250. http://dx.doi.org/10.1108/01425450810866514

\section{Appendix: Research Questionnaire}

This questionnaire relates to work environments. There are no wright and wrong answers to the items included in the questionnaire. A response to each item reflects your personal view and attitude.

Data collected through this instrument will be aggregated and used for research purposes only. All information provided will be kept confidential and no one will identify the answers of a particular respondent.The questionnaire will take few minutes of your valuable time. We appreciate taking the time to respond to each of the items as accurately as possible. We appreciate your cooperation and participation in this research work.

On behalf of the research team

Professor Mohamed Ibrahim, PhD., CGA

i. Please provide your answers to each of the following item

1) Indicate your Gender

_ Male Female

2) Indicate your age --------------- Years

3) Indicate your nationality

_ UAE National __ Non-UAE national

4) Indicate your highest level of education

Below Bachelor Degree (e.g., High school degree, high diploma)

Bachelor Degree

Graduate Degree (Master or PhD)

Other (please specify

5) Indicate your Marital Status

_ Single _ Married Others

6) Indicate the title of your position within the organization

7) How long have you been working for your organization?

Years

ii. The following six statements describe your degree of attachment to the organization you are currently employed with. Please place $(\sqrt{ })$ in the appropriate column indicating the degree to which each of the statements applies to you using the following scale:

\begin{tabular}{lllllll}
\hline 1 & 2 & 3 & 4 & 5 & 6 & 7 \\
\hline Strongly & Disagree & Slightly & Neither Agree & Slightly & Agree & Strongly \\
Disagree & & Disagree & Nor Disagree & Agree & & Agree \\
\hline
\end{tabular}




\begin{tabular}{|c|c|c|c|c|c|c|c|c|}
\hline No & Statement & 1 & 2 & 3 & 4 & 5 & 6 & 7 \\
\hline 1 & I am very happy being a member of this organization & & & & & & & \\
\hline 2 & I do not feel a strong sense of "belonging" to this organization (R) & & & & & & & \\
\hline 3 & I really feel as if this organization's problems are my own & & & & & & & \\
\hline 4 & I do not feel "emotionally attached" to this organization(R) & & & & & & & \\
\hline 5 & This organization has a great deal of personal meaning for me & & & & & & & \\
\hline 6 & I do not feel like "part of the family" at this organization(R) & & & & & & & \\
\hline
\end{tabular}

(i) For each of the following four items, you are provided with seven statements. Please the one that best represents your opinion or perception by placing a check mark $(\sqrt{ })$ in front of that statement.

a) Choose the ONE of the following statements that which best tells you how well you like your job:

1. I hate it.

2. I dislike it.

3. I don't like it.

4. I am indifferent to it.

5. I like it.

6. I am enthusiastic about it.

7. I love it.

b) Check one of the following statements to show HOW MUCH OF THE TIME you feel satisfied with your job:

1. All the time.

2. Most of the time.

3. A good deal of the time.

4. About half of the time.

5. Occasionally.

6. Seldom.

7 Never.

c) Check the ONE of the following statements which best tells how you feel about changing your job:

1. I would quit this job at once if I could get anything else to do.

2. I would almost take any other job in which I could earn as much as I am earning now.

3. I would like to change both my job and my occupation.

4. I would like to exchange my current job.

5. I am not eager to change my job, but I would do so if I could get a better job.

6. I cannot think of any job for which I would exchange.

7. I would not exchange my job for any other.

d) Check one of the following statements to show how you think you compare with other people:

1. No one likes his job better than I like mine.

2. I like my job much better than most people like theirs.

3. I like my job better than most people like theirs.

4. I like my job about as well as most people like theirs.

5. I dislike my job more than most people dislike theirs.

6. I dislike my job much more than most people dislike theirs.

7. No one dislikes his job more than I dislike mine. 
iii. On a scale of 1 (strongly disagree) to 7 (strongly agree), please indicate the extent to which you agree or disagree with each of the following statements by placing a check mark $(\sqrt{ })$ in the appropriate column

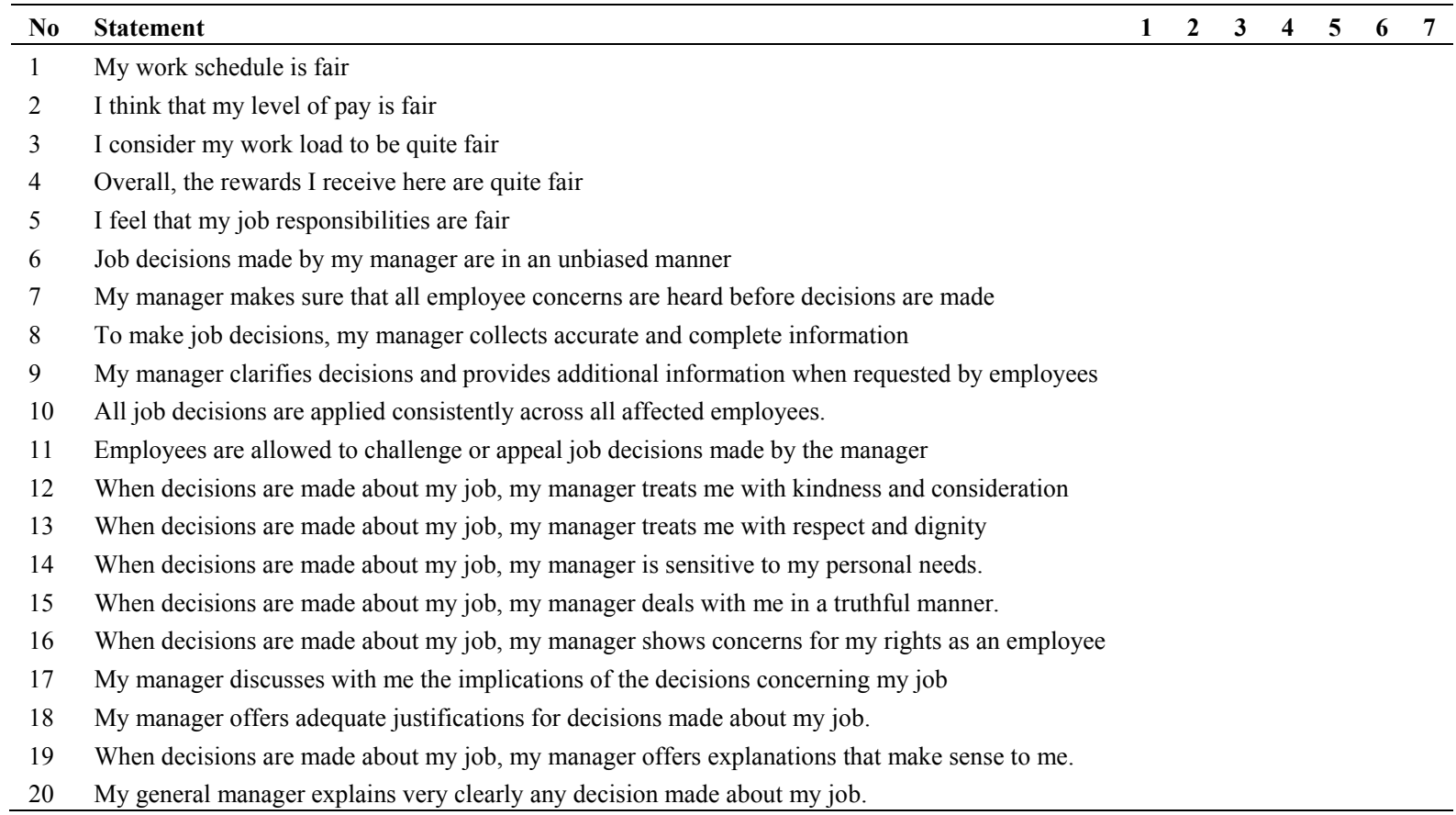

\section{Thank you for your Cooperation}

If you would like to receive a copy of the final research manuscript, please provide the following information:

Name:

Address:

E-mail:

\section{Copyrights}

Copyright for this article is retained by the author(s), with first publication rights granted to the journal.

This is an open-access article distributed under the terms and conditions of the Creative Commons Attribution license (http://creativecommons.org/licenses/by/3.0/). 